\title{
Telecommunication System Based on Fuzzy Graphs
}

\author{
Sovan Samanta* and Madhumangal Pal \\ Department of Applied Mathematics with Oceanology and Computer Programming, VidyasagarUniversity,Midnapore - 721102, India
}

\begin{abstract}
Telecommunication is one of the unavoidable utilities of daily life. Telecommunication service providers have data records of its users. These records are represented by crisp graphs. Certain parameters like center persons, churn prediction, etc. are more perfectly calculated if the data are represented by fuzzy graphs. In this paper, we have introduced a fuzzy telecommunication network (FTN) using fuzzy graph theory.Star persons and related terms are defined in this fuzzy telecommunication network.A small example is described to illustrate the network. Churn prediction is a big issue for telecom service providers. This study introduces churn prediction in the fuzzy telecommunication network. New idea on measurement of churn prediction is presented here.
\end{abstract}

Keywords: Fuzzy graphs; Telecommunication; Center person;Churn prediction

\section{Introduction}

Communication is one of the most important aspects of human society and culture. Humansociety is developed with faster communication systems. Telecommunication is one of necessaryand unavoidable system in our daily life now. Some telecom companies, favored by people, areChina mobile, Vodafone, Telenor, Airtel, etc.

As of January 2012, China Mobile is the world's largest mobile phone service provider withabout 655 million subscribers. Vodafone is the world's second-largest mobile telecommunicationscompany measured by both subscribers and 2011 revenues, and had 439 million subscribersas of December 2011. Vodafone owns and operates networks in over 30 countries and haspartner networks in over 40 additional countries. At the end of 2010, Telenor's 203 million Subscribers made it one of the largest mobile phone service providers in the world. Bharti AirtelLimited, commonly known as Airtel, is an Indian telecommunication company that operatesin 20 countries across South Asia, Africa and the Channel Islands. Airtel is the fifth largesttelecom service provider in the world with over 243.336 million customers across 20 countries asof March 2012.

The telecom service providers make a statistics of customers to identify the star person's aswell as the persons who are churning. It is very hard and laborious to identify such persons.Hadden et al. [1] described about churn prediction using complaints data. Further, Nanavati et al. [2] discussed the structural properties of massive telecom call graphs.After that Dasgupta et al. [3] discussed on social ties and their relevance to churn in mobile telecom networks. Also, Gopal and Meher[4]introduced customer churn time prediction in mobile telecommunication industryusing ordinal regression. Some other works to measure the churn of telecom service providersare found in [5-7]. In all these works, churn of telecom service providers is not measuredexactly. Fuzzy concept is used here to calculate the churning probability of customers. Toidentify star and churning persons, we have introduced a telecommunication system called fuzzytelecommunication network (FTN). This representation of telecommunication system is designedby fuzzy graph theory. The churning and the center persons are also valuable from the serviceprovider's point of view. In this paper, we have presented a formula to find centrality of a personand the churning prediction of a person in a telecom network.

\section{Preliminaries}

Every kind of social group can be represented in terms of units or actors, composing this groupand relations between these units. This kind of representation of a social structure is called “Social Network". In a social network, every unit, usually called "social units" like a person, anorganization, a community, and so on, is represented as a node. A relation between two socialactors is expressed by a link. So every social network can be represented by a graph.

A graph is an ordered pair $G=(V, E)$, comprising a set $V$ of vertices or nodes together witha set $\mathrm{E}$ of edges or lines.

A walk [8] of a graph is an alternating sequence of points and lines $v \in V$ beginning and ending with points, in which each line is incident with the two points immediately preceding and following it. It is a trail if all the lines are distinct, and a path if all the points(and thus necessarily all the lines) are distinct. If the walk is closed, then, it is a cycle providedits $\mathrm{n}$ points are distinct and $\mathrm{n} \geq 3$. The length [8] of a walk $v_{0}, x_{1}, v_{0}, \ldots, v_{n}-1, x_{n}, v_{n}$ is $\mathrm{n}$, the number of occurrences of lines in it.

Centrality is a very important part of a social network. Different types of centrality are definedin literature. Degree centrality [9] is the number of ties incident upon a node. Betweenness centrality [10] is a measure of a node's centrality in a network equal to the number of shortestpaths from all vertices to all others that pass through that node.

In our earlier paper [11], we have shown that a social network can be represented by fuzzygraph and hence fuzzy social network has been introduced. We have also investigated its severalimportant features in this paper.

Now, fuzzy set and related terms are defined. A fuzzy set Aon a set $\mathrm{X}$ is characterized by a mapping $m: X \rightarrow[0,1]$, which is called the membership function. A fuzzy set is denoted byA $=(X, m)$. The support of $\mathrm{A}$ is $\operatorname{supp} A=\{x \in X \mid m(x) \neq 0\}$.

Definition 1: [12] A fuzzy graph $\phi\left(C_{k}\right)=\sigma\left(C_{k}\right)$ is a non-empty set $\mathrm{V}$ together with a pair of functions $\sigma: V \rightarrow[0,1]$ and $\mu: V \times V \rightarrow[0,1]$ such that for all $, y \in V, \mu(x, y) \leq \sigma(x) \wedge \sigma(y$ and $\mu$ is a symmetric fuzzy relation on $\sigma$. Here $\sigma(\mathrm{x})$ and $\mu(\mathrm{x}, \mathrm{y})$ represent the membership valueof the vertex $\mathrm{x}$ and of the edge $(\mathrm{x}, \mathrm{y})$ in $\xi$.

${ }^{*}$ Corresponding author: Sovan Samanta, Department of Applied Mathematics with Oceanology and Computer Programming,Vidyasagar University, Midnapore - 721 102, India, E-mail:ssamantavu@gmail.com

Received November 08, 2013; Accepted December 10, 2013; Published December 16, 20130

Citation: Samanta S, Pal M (2013) Telecommunication System Based on Fuzzy Graphs. J Telecommun Syst Manage 3: 110. doi:10.4172/2167-0919.1000110

Copyright: (c) 2013 Samanta S, et al. This is an open-access article distributed under the terms of the Creative Commons Attribution License, which permits unrestricted use, distribution, and reproduction in any medium, provided the original author and source are credited. 
Degree [13] of a node $v \in V$ of a fuzzy graph $\xi=(V, \sigma, \mu)$ is $d(v)=\sum_{u \neq v} \mu(u, v)$ for all $v \in V$.

For the fuzzy graph $\xi=(V, \sigma, \mu)$, two vertices $\mathrm{x}$ and $y$ in $\mathrm{V}$ are called adjacent if $\frac{1}{2} \min \{\sigma(x), \sigma(y)\} \leq \mu(x, y)$. The edge $(\mathrm{x}, \mathrm{y})$ of $\xi$ is called strong [3] if $\mathrm{x}$ and $\mathrm{y}$ are adjacent and it is called weak otherwise.

Telecommunication is the exchange of information over any distance by a telecommunication path. A complete, single telecommunication circuit consists of two stations, each equipped with a transmitter and a receiver. The medium of signal transmission can be electrical wire or cable, optical fiber or electromagnetic fields. The freespace transmission and reception of data by means of electromagnetic fields is called wireless.

A mobile phone is a wireless device that can make and receive telephone calls over a radio link while moving around a wide geographic area. It does so by connecting to a cellular network provided by a mobile phone service provider, allowing access to the public telephone network. Sim-card is a small electronic chip on which the mobile phone number is stored.

A prepaid mobile phone is a mobile phone for which credit is purchased in advance of service use. The post-paid mobile phone is a mobile phone in which user is billed after the fact according to their use of mobile services at the end of each month.

Churn is a term used by companies to denote the loss of customers.

Churn prediction is currently a relevant subject in data mining and has been applied in the field of banking [14], mobile telecommunication $[5,12]$, life-insurances [13], and others to find the prediction of persons who are going to leave the system.

Definition 2: [15] Directed fuzzy graph (fuzzy digraph) $\vec{\xi}=(V, \sigma, \vec{\mu})$ is a non-empty set $\mathrm{V}$ together with a pair of functions $\sigma: V[0,1]$ and $:: V \times V \rightarrow[0,1]$ such that for all $x, y \in V, \vec{\mu}(x, y) \leq \sigma(x) \wedge \sigma(y)$

Here $\vec{\mu}(x, y)$ represents the membership value of the directed edge $\overrightarrow{(x, y)}$. Since $\vec{\mu}$ is well defined, a fuzzy digraph has at most two directed edges (which must have opposite directions) between any two vertices. The loop at a vertex $\mathrm{x}$ is represented by $\vec{\mu}(x, x) \neq 0$. Here $\vec{\mu}$ need not be symmetric as $\vec{\mu}(x, y)$ and $\vec{\mu}(y, x)$ may have different values. The underlying crisp graph of directed fuzzy graph is the graph obtained except the directed arcs are replaced by undirected edges.

\section{A New Model of Telecommunication Network, FTN}

A telecommunication network is a social network. In this system, we propose a method to represent telecommunication network by fuzzy graph.

\section{Representation of telecommunication system by directed fuzzy graphs}

Let $V_{1}=\left\{c_{1}, c_{2} \ldots, c_{\lambda}\right\}$, where $\lambda$ is very large integer, be the set of all registered customers in the telecommunication network FTN and $V_{2}=\left\{c_{\lambda+1}, c_{\lambda+2} \ldots, c_{\varphi}\right\}$ be the outside customers connected to the members of FTN. Let $V=V_{1} \cup V_{2}$. The membership values of the customers are given by $\phi: V \rightarrow[0,1]$ and the membership values of the links between the customers are given by $\vec{\mu}: V \times V \rightarrow[0,1]$.Then, the telecommunication system is represented by a directed fuzzy graph $\vec{\xi}=(V, \phi, \vec{\mu})$.

The underlying fuzzy graph of $\vec{\xi}$ is denoted by $\vec{\xi}=(V, \sigma, \mu)$, where $\vec{\mu}: V \times V \rightarrow[0,1]$ such that $\mu(a, b)=\frac{\vec{\mu}(a, b)+\vec{\mu}(b, a)}{2}$ for all $a, b \in V$.

\section{Membership values of customers in FTN}

We introduce our model from a telecommunication network service provider's point of view. Anservice provider gives more importance to the customer having more connected people. Before the discussion of membership values of the social units, a co-related term, recognition number, is defined below. In every society, recognition of each person is measured by some members of the society. In FTN, we take the number of those members as recognition number. It is denoted by $\mathrm{n}$. This recognition number (n) may not equal for all social networks. But it should be pre-determined for a particular social network. For example, a social network may assume 3 as recognition number, i.e. for each new member of the social network, 3 persons' recommendation is necessary. Another social network may use another value of $n$.

Here $V_{1=}\left\{c_{1}, c_{2} \ldots c_{\lambda}\right\}$, where $\lambda$ is a large integer, be aset of registered people in the network FTN. Let $\sigma: V_{1} \rightarrow[0,1]$ be a mapping such that

$$
\vec{\mu}: V \times V \rightarrow[0,1]
$$

Wheren is fixed integer for the network and Iis the number of distinct connected people (i.e. distinct phone numbers) of the customer $c \in V_{1}$ per unit interval of time in the network.

\section{Membership values of customers of other network connected to FTN}

In real world, every group of people has several network mobile users. We are interested to those customers of other networks who are connected to the people of FTN. It is hard to collect all the data of these people, but the number of calls (with duration) of the customers of other networks which are connected to the customers of FTN, are available.

All service providers prepare their plans in such a way that people talk to others within same network by low call-charges. If a customer of a network X (say) talks to a customer of another network Y (say) during a large amount of time, then we can conclude that the customer of $\mathrm{X}$ has more friends within the same network $\mathrm{X}$, otherwise he/she will change his/her service provider to Y.

We assign the membership values to these customers for representation of FTN. Let $V_{2}=\left\{c_{\lambda+1,}, c_{\lambda+2, \ldots,}, c_{\varphi}\right\}$ be the other network people connected to some people of FTN.

Before the introduction of the membership values of customers of outside FTN, a co-related term "satisfied time of calling" is defined. If an outside customer of FTN, calls certain amount of time to customers of FTN, then the outside customer is also valuable for FTN. We take T, a real positive number, as fixed amount of time. If the call duration of an outside customer to FTN is greater than T, the customer is taken as valuable. This fixed amount of time is called Satisfied time of calling.

Let out going call time of $C \in V_{2}$ to any customer of FTN be $t$ and T be the satisfied time of calling of a customer to FTN. Let the mapping $\phi: V \rightarrow[0,1]$ such that $\phi\left(C_{k}\right)=\sigma\left(C_{k}\right)$ for all $C_{k} \in V_{1}$ and for all $C \in V_{2}$

$$
\vec{\xi}=(V, \phi, \vec{\mu})
$$

\section{Membership value of a link between two customers}

In real world, two people are very close in telecommunication when they talk more time over telephones. So strength between two friends depends on how much time they call to each other by phones per unit interval of time. We denote $\overline{\left(C_{i}, C_{j}\right)}$ if $\mathrm{C}_{i}$ calls $\mathrm{C}_{j}$ by phones where $C_{i} C_{j} \in V$.Let $\vec{\mu}: V \times V \rightarrow[0,1]$ be a mapping such that 
Citation: Samanta S, Pal M (2013) Telecommunication System Based on Fuzzy Graphs. J Telecommun Syst Manage 3: 110. doi:10.4172/2167-

$$
\vec{\mu}\left(C_{i}, C_{j}\right)=\left\{\begin{array}{cc}
\frac{t}{T}\left(\sigma\left(C_{i}\right) \wedge \sigma\left(C_{j}\right)\right), & \text { if } t \in[0, T] \\
\sigma\left(C_{i}\right) \wedge \sigma\left(C_{j}\right), & \text { if } t>T .
\end{array}\right.
$$

Wheretis the duration of call per unit interval of time and $\mathrm{T}$, satisfied time of calling is fixed positive real number for a network.

We denote $\vec{\mu}\left(C_{i}, C_{j}\right)$ as the membership value of the link $\overline{\left(C_{i} C_{j}\right)}$. Hence $\vec{\xi}=(V, \phi, \vec{\mu})$ represents the telecommunication system FTN.

Now, $\mu\left(C_{i}, C_{j}\right)=\frac{\vec{\mu}\left(C_{i}, C_{j}\right)+\vec{\mu}\left(C_{j}, C_{i}\right)}{2}$. Then, the underlying fuzzy graph of $\vec{\xi}=\xi(V, \phi, \mu)$.

\section{An example of the telecommunication system FTN}

We have taken a sample of customers $V_{1}=\left\{A_{1}, A_{2}, A_{3}, A_{4}, A_{5}, A_{6}, A_{7}, A_{8}, A_{9}, A_{10}, A_{11}, A_{12}, A_{13}, A_{14}, A_{15}, A_{16}, A_{17}, A_{18}, A_{19}, A_{20}\right\}$ in the network FTN and $V_{2}=\left\{B_{1}, B_{2}, B_{3}, B_{4}, B_{5}, B_{6}, B_{7}\right\}$ area set of customers of other networks. All the connections of customers are shown in (Figure 1).In the figure, the names in circles represent the customers of FTN and the names in squaresrepresent the customers outside of FTN but connected to FTN. We take recognition number as 4 and satisfied calling time as 40 minutes per interval of time.

To illustrate our model, we assumed that the customers are connected with some other peopleas per data given in (Table 1). Based

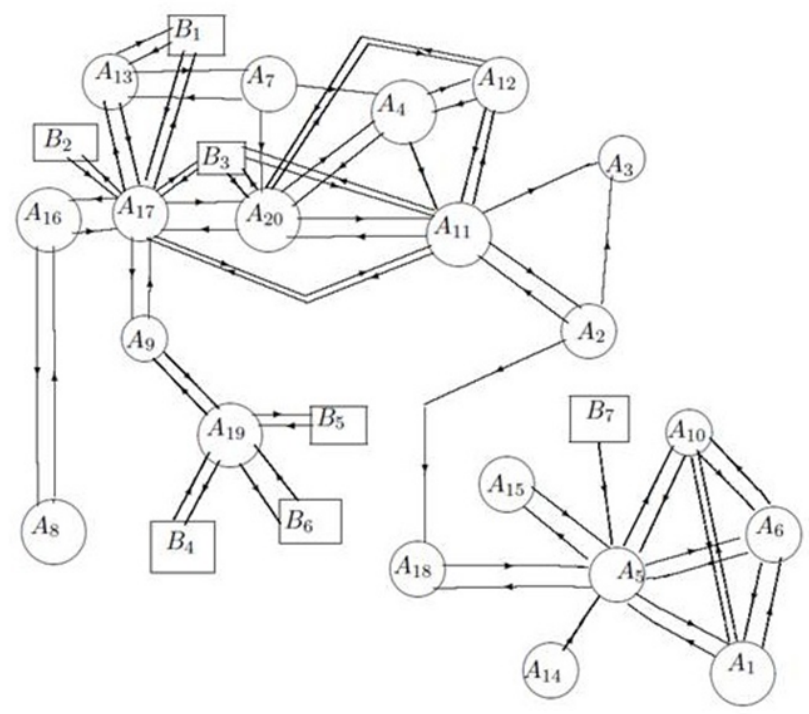

Figure 1: An example of telecommunication system.

\begin{tabular}{|c|c|c|c|c|c|}
\hline Customer & $\begin{array}{c}\text { Number of } \\
\text { connections }\end{array}$ & $\boldsymbol{\sigma}$-values & Customer & $\begin{array}{c}\text { Number of } \\
\text { connections }\end{array}$ & $\boldsymbol{\sigma}$-values \\
\hline $\mathrm{A}_{1}$ & 3 & $0: 75$ & $\mathrm{~A}_{11}$ & 7 & 1 \\
\hline $\mathrm{A}_{4}$ & 4 & 1 & $\mathrm{~A}_{12}$ & 3 & $0: 75$ \\
\hline $\mathrm{A}_{5}$ & 7 & 1 & $\mathrm{~A}_{13}$ & 3 & $0: 75$ \\
\hline $\mathrm{A}_{3}$ & 2 & $0: 5$ & $\mathrm{~A}_{14}$ & 1 & $0: 25$ \\
\hline $\mathrm{A}_{2}$ & 3 & $0: 75$ & $\mathrm{~A}_{15}$ & 1 & $0: 25$ \\
\hline $\mathrm{A}_{6}$ & 3 & $0: 75$ & $\mathrm{~A}_{16}$ & 2 & $0: 5$ \\
\hline $\mathrm{A}_{7}$ & 3 & $0: 75$ & $\mathrm{~A}_{18}$ & 2 & $0: 5$ \\
\hline $\mathrm{A}_{8}$ & 1 & $0: 25$ & $\mathrm{~A}_{17}$ & 5 & 1 \\
\hline $\mathrm{A}_{9}$ & 2 & $0: 5$ & $\mathrm{~A}_{19}$ & 4 & 1 \\
\hline $\mathrm{A}_{10}$ & 3 & $0: 75$ & $\mathrm{~A}_{20}$ & 6 & 1 \\
\hline
\end{tabular}

Table 1: List of customers of FTN with membership values.

\begin{tabular}{|c|c|}
\hline Name of customer & Total out-going call duration to FTN \\
\hline $\mathrm{B}_{1}$ & 90 \\
\hline $\mathrm{B}_{2}$ & 10 \\
\hline $\mathrm{B}_{3}$ & 90 \\
\hline $\mathrm{B}_{4}$ & 30 \\
\hline $\mathrm{B}_{5}$ & 10 \\
\hline $\mathrm{B}_{6}$ & 10 \\
\hline $\mathrm{B}_{7}$ & 30 \\
\hline
\end{tabular}

Table 2: List of other network customers with out-going call duration.

\begin{tabular}{|c|c|}
\hline Name of customer & Membership values \\
\hline $\mathrm{B}_{1}$ & 1 \\
\hline $\mathrm{B}_{2}$ & 0.25 \\
\hline $\mathrm{B}_{3}$ & 1 \\
\hline $\mathrm{B}_{4}$ & 0.75 \\
\hline $\mathrm{B}_{5}$ & 0.25 \\
\hline $\mathrm{B}_{6}$ & 0.25 \\
\hline $\mathrm{B}_{7}$ & 0.75 \\
\hline
\end{tabular}

Table 3: List of other network customers connected to FTN.

on this data, the $\sigma$-values of each customer is evaluatedand shown in column 3 and 6 of the same table.

From (Table 1), we see that $A_{1} \in V_{1}$ has 3 connected customers. So $\phi\left(A_{1}\right)=\sigma\left(A_{1}\right)=\frac{3}{4}=0.75$.

Similarly, other membership values of units are calculated. Now to assign the membership values of the customers outside FTN, we have to collect the amount of time of calling of telephone calls to the customers of FTN. The amount of time is shown in (Table 2). For example, B1 has callingtime (out-going) 80 minutes to $A_{13}$ and 10 minutes to $A_{17}$. So total outgoing calling time ofB1 to FTN is 90 minutes. This amount of time is bigger than the satisfied calling time. So $\phi\left(B_{1}\right)=1$. Again, the calling time of $\mathrm{B}_{4}$ to FTN (to $\mathrm{A}_{19}$ ) is 30 minutes. So $\phi\left(B_{4}\right)=\frac{30}{40}=0.75$.

Similarly, the membership values of the members of $\mathrm{V}_{2}$ are depicted in (Table 3).

Now the link membership values of customers within FTN are shown in (Table 4). For example,

$\mu\left(\mathrm{A}_{11}, \mathrm{~A}_{3}\right)=\frac{t}{T} \phi\left(\mathrm{A}_{11}\right) \wedge \phi\left(\mathrm{A}_{3}\right)=\frac{20}{40} \times 0.5=0.25$ etc. In $\quad$ Table $\quad 5, \quad$ link membership values betweentwo customers, one from FTN and other from other network are listed below.

\section{Center Person in FTN}

\section{Star person}

In a telecommunication network, a person is called star person if his/her number of friends is more than $\mathrm{M}$, where $\mathrm{M}$ is an integer, decided by the service provider. In general, friend $\left(\mathrm{F}_{2}\right)$ of friend $\left(\mathrm{F}_{1}\right)$ is important to a person $(\mathrm{P})$ in telecommunication if the friend $\left(\mathrm{F}_{2)}\right.$ of friend is star person in the network. We now define centrality of a person in the telecommunication system FTN below. In FTN, if a unit $\mathrm{P}_{\mathrm{f}}$ is directly connected with the unit $\mathrm{P}$, then we say that $\mathrm{P}_{\mathrm{f}}$ is distance- 1 friend of $\mathrm{P}$. The set of all distance- 1 friends of $\mathrm{P}$ be denoted by $\mathrm{d}_{1}(\mathrm{P})$. That is,

$$
d_{1}(P)=\left\{P_{i} \in V: P_{i} \text { is a distance- } 1 \text { friend of } P\right\}
$$

If there is a shortest path (i.e. minimum number of links) between $\mathrm{P}$ and $P_{f}^{*}$, a star customer, containing kegdes or links, then $P_{f}^{*}$ is a distance- $k$ star friend of P. Let 
Citation: Samanta S, Pal M (2013) Telecommunication System Based on Fuzzy Graphs. J Telecommun Syst Manage 3: 110. doi:10.4172/21670919.1000110

Page 4 of 6

\begin{tabular}{|c|c|c|c|c|c|c|c|c|c|c|c|}
\hline Link & Calling time & $\vec{\mu}_{\text {- values }}$ & Link & Calling time & $\vec{\mu}_{\text {- values }}$ & Link & Calling time & $\vec{\mu}_{\text {- values }}$ & Link & Calling time & $\vec{\mu}_{\text {-values }}$ \\
\hline $\overrightarrow{\left(A_{16}, A_{8}\right)}$ & 100 & 0.25 & $\overline{\left(A_{16}, A_{8}\right)}$ & 20 & 0.125 & $\overrightarrow{\left(B_{1}, A_{13}\right)}$ & 80 & 0.75 & $\overline{\left(B_{1}, A_{13}\right)}$ & 70 & 0.75 \\
\hline $\overrightarrow{\left(A_{16}, A_{17}\right)}$ & 20 & 0.25 & $\overline{\left(A_{16}, A_{17}\right)}$ & 20 & 0.25 & $\overrightarrow{\left(B_{1}, A_{17}\right)}$ & 10 & 0.25 & $\overline{\left(B_{1}, A_{17}\right)}$ & 10 & 0.25 \\
\hline $\overrightarrow{\left(A_{17}, A_{9}\right)}$ & 60 & 0.5 & $\overline{\left(A_{17}, A_{9}\right)}$ & 10 & 0.125 & $\overline{\left(B_{2}, A_{17}\right)}$ & 10 & 0.0625 & $\overline{\left(B_{2}, A_{17}\right)}$ & 10 & 0.0625 \\
\hline$\overline{\left(A_{17}, A_{20}\right)}$ & 30 & 0.75 & $\overline{\left(A_{17}, A_{20}\right)}$ & 20 & 0.5 & $\overrightarrow{\left(B_{3}, A_{17}\right)}$ & 10 & 0.25 & $\overline{\left(B_{3}, A_{17}\right)}$ & 15 & 0.375 \\
\hline$\overline{\left(A_{17}, A_{13}\right)}$ & 20 & 0.25 & $\overline{\left(A_{17}, A_{13}\right)}$ & 60 & 0.5 & $\overline{\left(B_{3}, A_{20}\right)}$ & 40 & 1 & $\overline{\left(B_{3}, A_{20}\right)}$ & 80 & 1 \\
\hline$\overline{\left(A_{17}, A_{11}\right)}$ & 30 & 0.75 & $\overline{\left(A_{17}, A_{11}\right)}$ & 05 & 0.125 & $\overrightarrow{\left(B_{3}, A_{11}\right)}$ & 40 & 1 & $\overline{\left(B_{3}, A_{11}\right)}$ & 20 & 0.5 \\
\hline$\overline{\left(A_{9}, A_{19}\right)}$ & 50 & 0.5 & $\left(A_{9}, A_{19}\right)$ & 10 & 0.125 & $\overrightarrow{\left(B_{4}, A_{19}\right)}$ & 30 & 0.5625 & $\overline{\left(B_{4}, A_{19}\right)}$ & 10 & 0.1875 \\
\hline$\overline{\left(A_{20}, A_{11}\right)}$ & 40 & 1 & $\overline{\left(A_{20}, A_{11}\right)}$ & 20 & 0.5 & $\overrightarrow{\left(B_{5}, A_{19}\right)}$ & 10 & 0.0625 & $\overline{\left(B_{5}, A_{19}\right)}$ & 60 & 0.25 \\
\hline$\overline{\left(A_{20}, A_{4}\right)}$ & 35 & 0.875 & $\left(A_{20}, A_{4}\right)$ & 10 & 0.25 & $\overrightarrow{\left(B_{6}, A_{19}\right)}$ & 10 & 0.0625 & $\overline{\left(B_{6}, A_{19}\right)}$ & 20 & 0.125 \\
\hline$\overline{\left(A_{20}, A_{12}\right)}$ & 80 & 0.75 & $\left(A_{20}, A_{12}\right)$ & 30 & 0.562 & $\overrightarrow{\left(B_{7}, A_{5}\right)}$ & 30 & 0.5625 & & & \\
\hline
\end{tabular}

Table 5: Link membership values of members of outside FTN but connected with FTN.

moreimportantthandistance- 4 star friends, and so on. The linguistic term "more important" can be representedbyweights. Let $w_{k}, 0 \leq w_{k} \leq 1$ be the weight whichrepresents the importance between the distance- $\mathrm{k}$ friends. Theweights gradually decrease if the distance between the friends increases. Thus $w_{1} \geq w_{2} \ldots \geq w_{k} \geq \ldots$ Let $\mathrm{u}_{1}\left(=\mathrm{P}_{\mathrm{i}}\right), \mathrm{u}_{2}, \mathrm{u} 3 \ldots \mathrm{u}_{\mathrm{k}}\left(=\mathrm{P}_{\mathrm{j}}\right)$ be thevertices on the path between $P_{i}$ and $P_{j}$. We define fuzzy distance $\mathrm{D}_{\mathrm{f}}\left(\mathrm{P}_{\mathrm{i}} \mathrm{P}_{\mathrm{j}}\right)$ between $\mathrm{P}_{\mathrm{i}}$ and $\mathrm{P}_{\mathrm{j}}$ along this path as $D_{f}\left(P_{i}, P_{j}\right)=\sum_{l=1}^{k-1} \mu\left(u_{1}, u_{l+1}\right)$.

In a network, it may be observed that there are multiple paths between two vertices. InFTN, we consider those paths of same length whose fuzzy distance $\mathrm{D}_{\mathrm{f}}$ is maximum. If thereare $k$ edges inthis path of maximum fuzzy distance, then we denote this distance by $D^{k}$ i.e, $D_{f}^{k}\left(\mathrm{P}_{\mathrm{i}}, \mathrm{P}_{\mathrm{j}}\right)$ represents the fuzzydistance between the vertices $\mathrm{P}_{\mathrm{i}}$ and $\mathrm{P}_{\mathrm{i}}$ in FTN along a certainpath containing exactly $\mathrm{k}$ edges. Forsimplicity,we consider the friends of a customer of distancep, i.e., we take up to distance-p friends. Now we definethe centrality $\mathrm{C}(\mathrm{P})$ of a social unit $\mathrm{P}$ of FTN as follows

$$
C(P)=\sum_{u_{1} \in d_{1}(P)} w_{1} D_{f}^{1}\left(P, u_{1}\right)+\sum_{u_{2} \in d_{2}^{\prime \prime}(P)} w_{2} D_{f}^{2}\left(P, u_{2}\right)+\ldots+\sum_{u_{p} \in d_{p}^{\prime \prime}(P)} w_{p} D_{f}^{p}\left(P, u_{p}\right) .
$$

In this measurement, the importance of close friend is given more than the next to close friendand gradually decreases the furthest friend. The importances are introduced by incorporating the weight $w_{i}$, for distance- $i$ friend, $i=1,2,3 \ldots$

In fuzzy social network (FSN), centrality [12] of a person was defined as the weighted sum of fuzzy distances of connected persons along certain paths. Here centrality of a customer in FTN is the weighted sum of fuzzy distances of directly connected customers and star customers connected by a certain path.

\section{Example of center persons in FTN}

Here we assumed that $\mathrm{M}=4$, i.e. we set a customer as a star person if his/her number of friends is greater than or equal to 4 (This assumption of $\mathrm{M}=4$ is arbitrary and also to simplify the calculation). Also, we take maximum acceptable length from a customer to a star customer is 10 and $w_{1}=1, w_{2}=0.9, w_{3}=0.8, \ldots w_{10}=0.1$. Now we find the centrality of the customer " $\mathrm{A}_{20}$ ". In the described example (see Section3.5) of FTN,

$$
d_{1}\left(A_{20}\right)=\left\{A_{17}, B_{3}, A_{7}, A_{12}, A_{4}, A_{11}\right\} .
$$

So 
$\sum_{u_{1} \in d_{1}} D_{f}^{1}\left(A_{20} u_{1}\right)=\mu\left(A_{17}, A_{20}\right)+\mu\left(B_{3}, A_{20}\right)+\mu\left(A_{7}, A_{20}\right)+\mu\left(A_{12}, A_{20}\right)+\mu\left(A_{4}, A_{20}\right)+\mu\left(A_{11}, A_{20}\right)=3.828$

In the network, $\mathrm{A}_{19}$ and $\mathrm{A}_{5}$ are the star persons among distance- $i$ customers, $i=2,3, \ldots 10$. Here $d_{3}^{* 1^{5}}\left(A_{20}\right)=\left\{A_{19}\right\}$ and $d_{4}^{* \prime}\left(A_{20}\right)=\left\{A_{5}\right\}$. So

$$
\begin{aligned}
& \sum_{u_{3} \in d_{3}^{*}} D_{f}^{3}\left(A_{20}, u_{3}\right)=\mu\left(A_{17}, A_{20}\right)+\mu\left(A_{17}, A_{9}\right)+\mu\left(A_{9}, A_{19}\right)=1.25 . \\
& \sum_{u_{4} \in d_{4}^{* *}} D_{f}^{4}\left(A_{20}, u_{4}\right)=\mu\left(A_{20}, A_{11}\right)+\mu\left(A_{11}, A_{2}\right)+\mu\left(A_{2}, A_{18}\right)+\mu\left(A_{18}, A_{5}\right)=2 .
\end{aligned}
$$

So certainly of

$$
\begin{aligned}
& A_{20}, C\left(A_{20}\right)=\sum_{u_{1} \in d_{1}^{\prime}\left(A_{20}\right)} D_{f}^{1}\left(A_{20}, u_{1}\right)+\sum_{u_{2} \in d_{2}^{*}\left(A_{20}\right)} 0.9 \times D_{f}^{2}\left(A_{0}, u_{2}\right)+ \\
& \ldots+\sum_{u_{10} \in d_{p}^{d^{\prime \prime}}\left(A_{20}\right)} 0.1 \times D_{f}^{A_{20}}\left(P, u_{10}\right)=3.828+0.8 \times 1.25+0.7 \times 2=6.228 .
\end{aligned}
$$

\section{Churn Prediction}

Churn of customers in telecommunication is a big problem for service providers. Churn problem occurs in prepaid mobile system mostly. So making a list of churning persons is an important task for service providers. Now, people feel luxury with many sim cards. So better offers from any of telecom service providers are accepted easily by people.Besides portability is easy now.So people change their mobile service provider due to minor causes. We are aware of the fact that calling within same service provider have more facility. So if strong persons decide to change their mobile service providers, then sometimes their followers do the same. Besides, outgoing or incoming calls of a phone number measure the stability in the network. If a person's outgoing calls increase or remain the same compared to the previous interval of time, then the service providers have nothing to worry. Similarly, one of other factors which indicate the activities of a customer is number of distinct phone numbers to which the customer is connected. If the number of connected customers in particular interval of time is rapidly decreases, then the customer may be churned in future. If number of outgoing calls per unit interval of time decrease, we calculate the decrease rate as

$$
D_{o}=\frac{\operatorname{Re} \text { duction of time of outgoing calls from previous int erval of time }}{\text { Total time of outgoing calls in previous int erval of time }}
$$

If number of friends decrease, then the rate of decrease is denoted as DF and defined as

$$
D_{F}=\frac{\operatorname{Re} \text { duction of number of friends from previous int erval of time }}{\text { Total number of friends in previous int erval of time }}
$$

If number of incoming calls decrease, decrease rate is denoted as DI and defined as

$$
D_{I}=\frac{\operatorname{Re} \text { duction of time of inco } \min g \text { calls from previous int erval of time }}{\text { Total time of inco } \min g \text { calls in previous int erval of time }}
$$

The measure of churn prediction of a customer $\mathrm{P}$ is denoted by $\chi(P)$ and defined by $\chi(P)=$

$$
\frac{w_{1} D_{F}+w_{2} D_{o}+w_{3} D_{I}}{w_{1}+w_{2}+w_{3}}
$$

Where w1, w2, w3 represent the weights associated with the significance of $\mathrm{D}_{\mathrm{O}} \mathrm{D}_{\mathrm{F}}$ and $\mathrm{D}_{\mathrm{I}}$. Generally $w_{1} \geq w_{2} \geq w_{3}$ as reduction of calling time is more significant than that of $\mathrm{D}_{\mathrm{F}}$ and $\mathrm{D}_{\mathrm{I}}$. Note that value of $\chi(P)$ lies between 0 and 1 . If this value of a customeris nearer to 1 , the customer is going to churn. Similarly, if the value is less than 0.5 , the serviceprovider is nothing to worry.

\section{Example of churn prediction in FTN}

Let in Example 3.5, $\mathrm{A}_{19}$ and $\mathrm{A}_{5}$ have been churned for a certain interval of time. Now we want to find the measurement of churn prediction of $A_{9}$ and $A_{10}$. We assumed that all other statistics are same except the statistics of $A_{9}$ and $A_{10}$.

\section{Churning Measurement of $\mathrm{A}_{9}$}

A9 has total outgoing call duration is 60 minutes (10 to $A_{17}$ and 50 to $\left.A_{19}\right)$. After churning of $A_{19}$ the reduction of outgoing call duration is 50 minutes, if all other statistics are same for the interval of time of consideration. Similarly, reduction of number of friends is 1 and reduction of time for in-coming calls is 10 minutes.

$$
\begin{aligned}
& D_{O}=\frac{50}{60}=0.833, D_{F}=\frac{1}{2}=0.5, D_{I}=\frac{10}{70}=0.14286 . \\
& \text { So } \chi\left(A_{9}\right)=\frac{0.833+0.5+0.14286}{3}=0.49195 \text { for } \omega_{1}=\omega_{2}=\omega_{3}=1 .
\end{aligned}
$$

\section{Churning measurement of $A_{10}$}

$$
\begin{gathered}
\text { In } 60 \\
D_{O}=\frac{60}{100}=0.667, D_{F}=\frac{1}{3}=0.333, D_{I}=\frac{80}{130}=0.61538 \\
\text { Therefore, } \chi\left(A_{10}\right)=\frac{0.667+0.333+0.61538}{3}=0.53846
\end{gathered}
$$

\section{Conclusion}

In this paper, Telecommunication network is represented by fuzzy graphs. It is not a general social network. Here, we also consider the customers of other networks. Centrality of customers in telecommunication is defined and illustrated with a small network. A formula to calculate churn prediction of customers is also provided. In the formula, the weight of the significance ofreduction of out-going call, friends and in-coming calls are assigned. This gives the flexibility to measure the churn prediction. The values of the weights are to be assigned by service provider as per their own decision.

Telecom companies make a list of influential or center persons. In this case, higher value of centrality of customers indicates that the customer is more central. Also, they want to retain the existing customers. Churning measure of customers indicates the customers' stability in the network. This study will help to make the list of such persons. We hope, fuzzy graph will be the backbone of future telecommunication system.

\section{Referneces}

1. Hadden J, Tiwari A, Roy R, Ruta D (2006) Churn prediction using complaints data. Proceedings of world academy of science engineering and technology 13: $158-163$.

2. Nanavati A, Gurumurthy S, Das G, Chakraborty D, Dasgupta K (2006) On the structural properties of massive telecom call graphs: findings and implications, In CIKM '06: Proceedings of the 15th ACM international conference on Information and knowledge manage- ment 435-444.

3. Dasgupta K, Singh R, Viswanathan B, Chakraborty D, Mukherjea S etal. (2008) Social ties and their relevance to churn in mobile telecom networks. In EDBT 08: Proceedings of the 11th international conference on Extending database technology New York USA, 668-677.

4. Gopal RK, Meher SK (2008)Customer churn time prediction in mobile telecommunication industry using ordinal regression Lecture Notes in Computer Science 5012: 884-889.

5. Chu B, Tsai M, and Ho C (2007) Toward a hybrid data mining model for customer retention. Knowledge-Based Systems 20: 703-718.

6. Euler $\mathrm{T}(2005)$ Churn prediction in telecommunication using mining mart.

7. Hung S, Yen DC, Wang $H$ (2006) Applying data mining to telecom churn management. Expert Systems with Applications 31: 515-524.

8. Harary F (2001) Graph Theory. Narosa Publishing House.

9. Freeman LC (1979) Centrality in networks: Conceptual clarification. Social Networks 1: 215-239.

10. Freeman LC (1977) A set of measures of centrality based on betweenness Sociometry $40: 35-41$.

11. Samanta S, Pal M, A new approach to social networks based on fuzzy graphs. To appear in Journal of Mass Communication and Journalism 
Citation: Samanta S, Pal M (2013) Telecommunication System Based on Fuzzy Graphs. J Telecommun Syst Manage 3: 110. doi:10.4172/21670919.1000110

Page 6 of 6

12. Rosenfeld, Fuzzy graphs, in: L.A. Zadeh, K.S. Fu, M. Shimura (Eds.), Fuzzy Sets and Their Applications, Academic Press, New York, 77-95, 1975.

13. Mordeson JN, Nair PS(2000) Fuzzy Graphs and Hypergraphs. PhysicaVerlag Heidelberg 46: 248.
14. Eslahchi C, Onagh BN (2006) Vertex strength of fuzzy graphs. International Journal of Mathematics and Mathematical Sciences 1-9.

15. Poel DVD, Larivire B (2004) Customer attrition analysis for financial services using proportional hazard models. European Journal of Operational Research 157: 196-217. 